\title{
Superplastic Behaviour and Microstructural Evolution in Stepped Tensile Deformation of Titanium Alloy
}

\author{
X.F. Xu, J.G. Zhang, C.F. Liu, G.C. Wang, and Z.H. Yun
}

\author{
(Submitted September 11, 2012; in revised form September 22, 2013; published online October 22, 2013)
}

\begin{abstract}
The effect of stepped tensile deformation at $850,900,950{ }^{\circ} \mathrm{C}$ on the elongation, microstructure, and mechanical characteristics of titanium alloy has been investigated. The stepped uniaxial tension (steppedUT) was composed of the following three steps in sequence: constant speed tension, clearance stage, and maximum $m$ superplasticity tension (MaxmSPT). Results showed that the maximum elongation of TC6 alloy between 850 and $950{ }^{\circ} \mathrm{C}$ through the Stepped-UT was $2053 \%$, in which the first engineering strain of constant speed tension was 2.0 , the following clearance time was $15 \mathrm{~min}$, and the MaxmSPT was finally carried on until failure. And the optimal elongations obtained by the MaxmSPT and constant speed tensile method were 1347 and $753.9 \%$ at $850{ }^{\circ} \mathrm{C}$, respectively. The true stress-strain curves showed the strain rate sensitivity index $\mathrm{m}$ of the alloy in the stepped-UT was higher than the one in the single step of the MaxmSPT. Moreover, the microstructure of TC6 alloys in the stepped superplastic deformation was observed and the grain refinement was found. The grain refinement and true stress-strain curves of TC6 alloys were all affected by preplanned engineering strain and temperatures. The results also showed the joint action of the dynamic recrystallization and static or meta-dynamic recrystallization refined the grains, improved the structure property, and induced the plasticity enhancement.
\end{abstract}

Keywords plasticity enhancement, recrystallization, stepped superplastic deformation, titanium alloy

\section{Introduction}

It is widely believed that superplasticity is a characteristic of equiaxed, stable, fine-grained materials, consisting primarily of high-angle grain boundaries, when they are deformed in tension at relatively high temperatures. The phenomenon is associated with the high strain-rate sensitivity of flow stress (high $m$ value) which causes a high resistance to necking, and hence leads to the high tensile strains. There is a strongly promoted, although not unanimous, view that grain boundary sliding plays a dominant role in superplastic flow (Ref 1, 2).

Titanium alloys have been widely used in the aerospace, automotive, chemical, and bio-medical engineering due to their excellent properties, such as high strength to weight ratio, excellent resistance against corrosion and good high heatdurability (Ref 3 ). In the past several years, a number of research efforts have been made to investigate the superplastic deformation process of titanium alloys. The microstructural evolution and superplastic properties have been reported for Ti-6Al-4V alloy (Ref 4-6), and the superplastic behaviors of titanium alloys have been investigated in some reports (Ref 7,8). In addition,

X.F. Xu and G.C. Wang, School of Aviation Manufacturing Engineering, Nanchang Hangkong University, Nanchang 330063 Jiangxi, China; J.G. Zhang, Capital Aerospace Machinery Company, Beijing 100076, China; and C.F. Liu and Z.H. Yun, AVIC Jiangxi Hongdu Aviation Industry Group Corporation limited, Nanchang 330024, China. Contact e-mail: xfwinzy@163.com. the ways and means of enhancing the superplasticity of titanium alloys are also extensively investigated. Thermohydrogen processing (THP) of titanium alloys has recently become an important research topic which can improve the superplasticity, mechanical properties and refine the casting microstructure of the materials with addition of hydrogen (Ref 9-11). The ultrafined Ti-6Al-4V alloy with grain size of about $0.5 \mu \mathrm{m}$ and superplastic elongation of over $9000 \%$ is obtained through the protium treatment (Ref 12). In addition, the superplasticity of Ti-6Al-4V alloy is also enhanced by severe plastic deformation and dynamic globularization (Ref 13,14$)$. The $\mathrm{Nb}$ content has an effect on the superplasticity of Ti-25Al-xNb alloy (Ref 15). Zhu et al. (Ref 16) used the two-step deformation method to increase the ductility of the commercially pure titanium alloy from 188 to $243 \%$, in which the temperature of every step was different. Wang et al. (Ref 17-19) introduced a novel concept of the maximum $\mathrm{m}$ superplasticity deformation (MaxmSPD) in which the maximum $m$ value was always maintained through dynamic control and adjustment of deformation strain rate to insure the forming material in the optimum superplasticity state all the time. He obtained the optimal elongation of $2300 \%$ for Ti-6.5AL-3.5Mo-1.5Zr-0.3Si alloy without grain refinement treating through the MaxmSPD tensile test at $900{ }^{\circ} \mathrm{C}$, while their optimal elongations attained by the constant speed and constant strain rate tensile test were 1100 and $1147 \%$ at the same temperature, respectively.

In this paper, the stepped uniaxial tension (Stepped-UT) based on the control of forming process was proposed and its process consisted of constant speed tension, clearance stage, and maximum $\mathrm{m}$ superplasticity tension (MaxmSPT) in sequence. The effect of preplanned engineer strain on the elongation, microstructure evolution, and mechanical characteristics of the titanium alloy was investigated. The aim of this work reported in this paper is to examine the factors influencing 
the tensile ductility in this type of alloys in order to promote the scientific understanding and to improve the properties of cast TiAl alloys. The project will explore the optimum superplastic deformation model to open up a new way with a high theoretical and practical value.

\section{Experimental Methods and the Rationale}

\subsection{Maximum m SPD}

The rheological behavior of superplastic materials in SPD process is represented by the Backofen equation in the following:

$\sigma=K \dot{\varepsilon}^{m}$

where $\sigma$ is the plastic flow stress, $\dot{\varepsilon}$ is the strain-rate, $m$ is the strain-rate sensitivity exponent and $K$ is a material-related constant. Among these parameters, $m$ is the most important parameter in SPD. It represents the resistance to necking in tensile test. Usually, the greater is the $m$ value, the better is the resistance to necking and the better is the superplasticity. Since misdependent on strain rate, the maximum $m$ value has a corresponding strain-rate, which is the so-called optimal strain-rate. However, the maximum $m$ and its corresponding optimal strain-rate vary in SPD process. This is the reason why the optimal superplasticity status at which the maximum $m$ of the material occurs is difficult to obtain.

To dynamically measure the $\mathrm{m}$ value, the following equations are derived from Eq 1 considering the cyclic variation of strain rate in the SPD process.

$m=\frac{\log \left(P_{\mathrm{B}} / P_{\mathrm{A}}\right)}{\log \left(V_{2} / V_{1}\right)}$

$m=\frac{\log \left(P_{\mathrm{B}} / P_{\mathrm{C}}\right)}{\log \left(V_{2} / V_{1}\right)}$

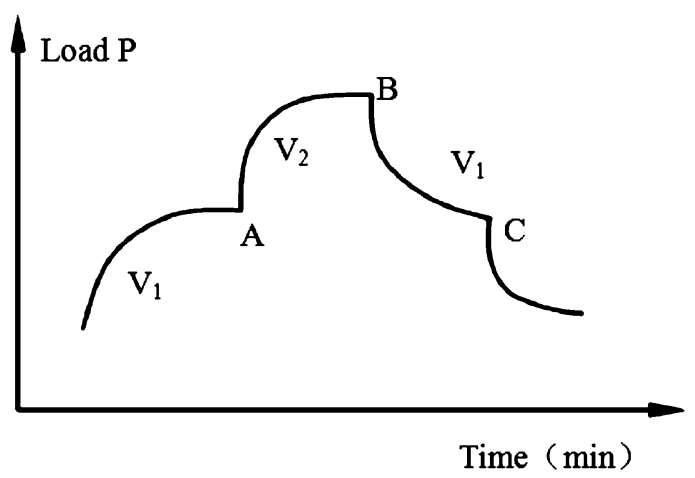

Fig. 1 Loading-time curve from the measurement of the $m$ value
In the above equations, Eq 2 is applied to the increasing strain rate scenario, whereas Eq 3 is applied to the decreasing strain rate scenario. $V_{1}$ and $V_{2}$ are the velocity before and after the velocity change and $P_{\mathrm{B}}$ and $P_{\mathrm{A}}$ are the corresponding deformation loads. Figure 1 illustrates these notations and the cyclic change of deformation speed. During the cyclic change of strain rate, the deformation velocity change was continuous, either increasing or decreasing. A series of $V_{\mathrm{i}}$ and $P_{\mathrm{i}}$ were thus dynamically recorded and measured. Based on Eqs 2 and 3, the instantaneous $\mathrm{m}$ was determined. According to the maximum $m$ principle, the deformation velocity could then be controlled and adjusted in such a way that the deformation velocity was always kept in a status at which the maximum $m$ was maintained. Since the maximum $m$ was kept during the entire SPD process, the optimal superplasticity condition could thus be maintained.

\subsection{Stepped Tensile Superplastic Deformation}

In the innovative stepped forming method, the deformation process is divided into two steps and each step can choose individually constant speed method, constant strain rate method, or the maximum $m$ value method (as shown in Fig. 2). The forming way and strain of every step, clearance time between two steps are controlled in deformation process in order to facilitate the grain refinement, structure property improvement, and plasticity enhancement.

The Stepped-SPD way added the clearance stage and its each forming step was engaged in the dissimilar deformation type, and this was different from the single-step deformation process. The clearance stage between the two forming steps resembled the heat-treating process in which the force acting on the sample in the first step was unloaded and then the sample was kept in the state of thermal retardation for the preplanned time. And it is well-known that the structure property and deformability of material can be improved through that heat treating process. Thus, the Stepped-SPD way is able to obtain the higher plasticity than the single-step forming method. Figure 2 indicates that the schematic diagram of the SteppedSPD process has two forming steps. In this tensile experiment, the first step was the constant speed tension and the second step was the MaxmSPD tension.

\subsection{Materials and Sample Preparation}

The test material is titanium alloy of TC6 belonging to the $(\alpha+\beta)$ type. Its nominal composition is Ti-6Al-2.5Mo-1.5Cr$0.5 \mathrm{Fe}-0.3 \mathrm{Si}$ in which $\mathrm{Al}$ content is $5.5-7.0 \%$ and Mo content is $2.0-3.0 \%$. Its phase transition point is at $(970 \pm 20){ }^{\circ} \mathrm{C}$. And the microstructure of the original material showed an average grain size between 6 and $7 \mu \mathrm{m}$. The sample dimension is shown in Fig. 3. From that figure, it can be found that the effective gauge dimensions are $\varnothing 5 \mathrm{~mm} \times 15 \mathrm{~mm}$.

Superplastic tensile test was carried out in SANS-CMT 4104 electronically tensile tester with computer control system

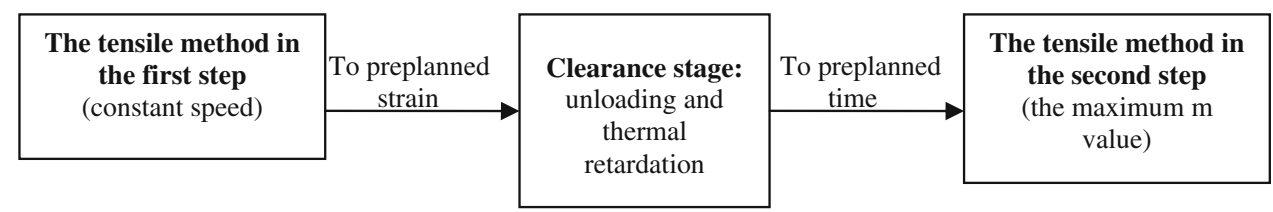

Fig. 2 Program of two steps superplastic tensile test 
and the heating device. Tensile specimen was protects with BJD-1 glass lubricant against oxidation at the high temperature deformation.

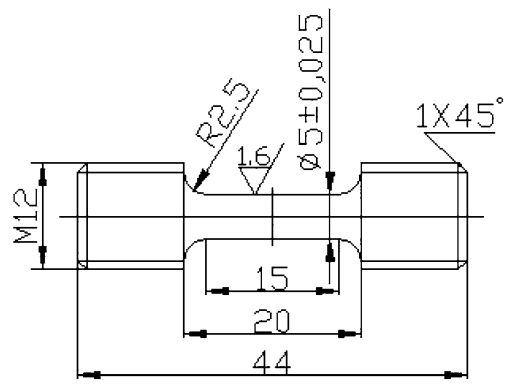

Fig. 3 Dimensions of the sample for tensile test
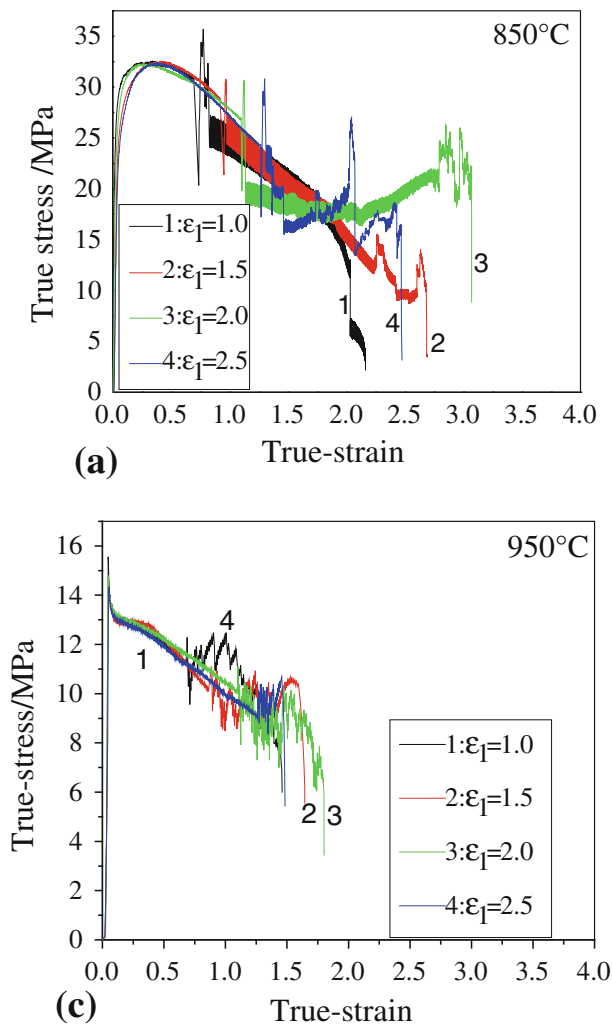

\section{Results and Discussion}

\subsection{Mechanical Behaviour of Titanium Alloy in Stepped-SPD}

The true stress-strain curves obtained from the stepped tensile experiments are shown in Fig. 4. As the strain increased, the former part of these curves standing for the constant speed tension was steady and gradual and the latter part representing the Maxm SPD tension was undulatory, which revealed that the stress was influenced prominently by speed change. When the pre-strain was different at the same temperature, the stress value nearly changed at the stage of constant-speed tensile and the one of the second step fluctuated significantly in the stressstrain curves of TC6 titanium alloy. The pre-strain of the first step had effect on the whole strain in the stepped-SPD at the same temperature. When the pre-strain was too low or too high,

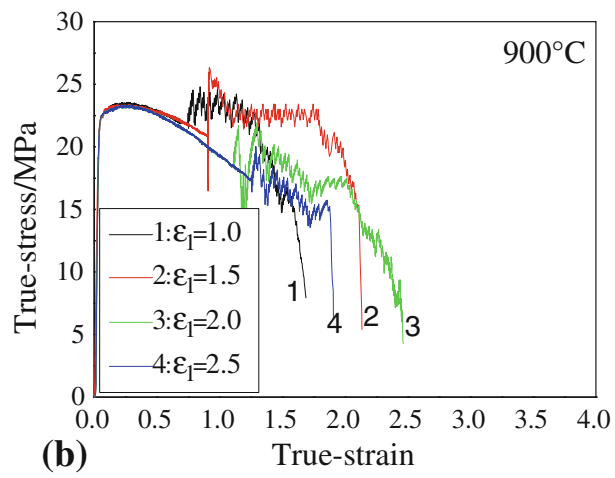

(b)

True-strain

Fig. 4 The stress-strain curves of TC6 with different pre-strain at the different temperature (a) $850{ }^{\circ} \mathrm{C}$ (b) $900{ }^{\circ} \mathrm{C}$ (c) $950{ }^{\circ} \mathrm{C}$
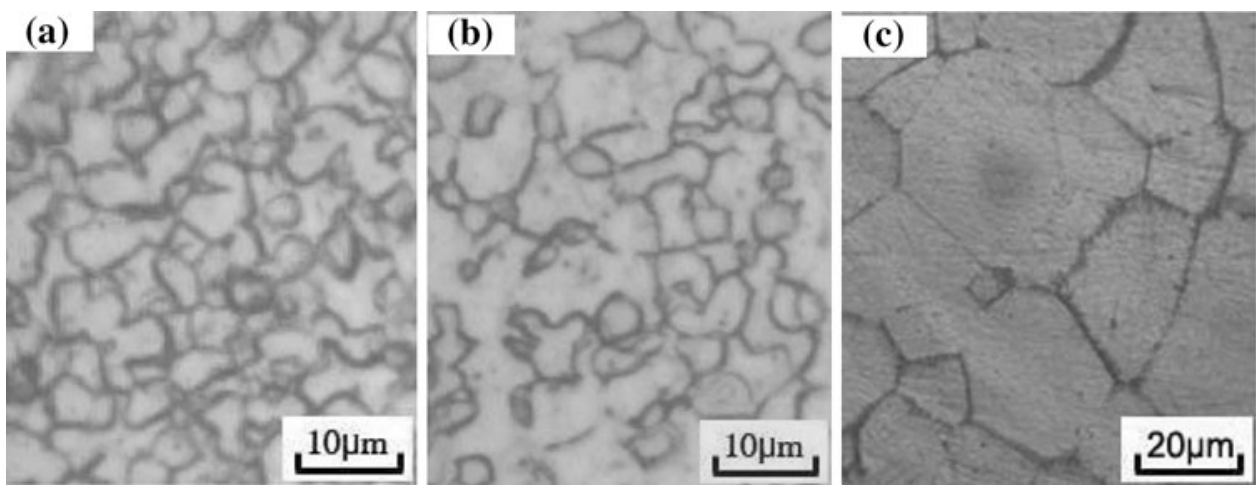

Fig. 5 The microstructure near the fracture at the pre-strain of 1.0 (a) $850{ }^{\circ} \mathrm{C}$ (b) $900{ }^{\circ} \mathrm{C}$ (c) $950{ }^{\circ} \mathrm{C}$ 

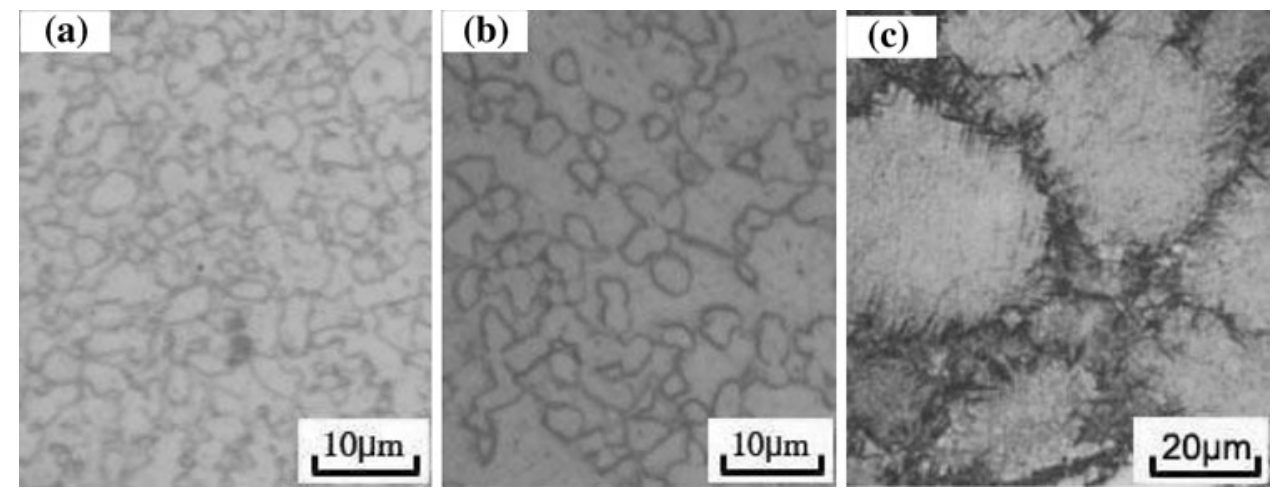

Fig. 6 The microstructure near the fracture at the pre-strain of 1.5 (a) $850{ }^{\circ} \mathrm{C} \mathrm{(b)} 900{ }^{\circ} \mathrm{C}$ (c) $950{ }^{\circ} \mathrm{C}$
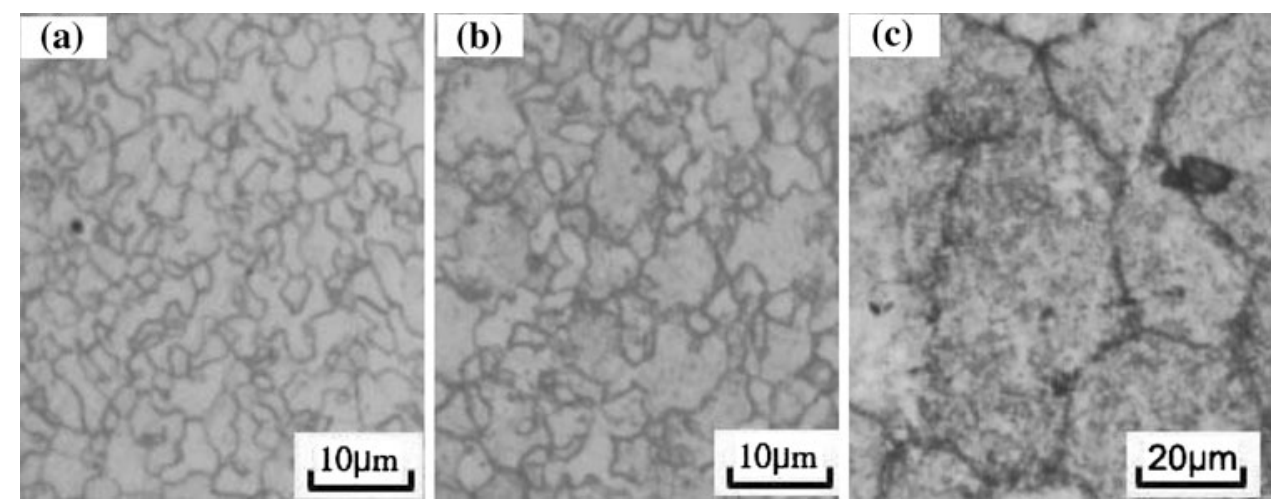

Fig. 7 The microstructure near the fracture at the pre-strain of 2.0 (a) $850{ }^{\circ} \mathrm{C} \mathrm{(b)} 900{ }^{\circ} \mathrm{C}$ (c) $950{ }^{\circ} \mathrm{C}$
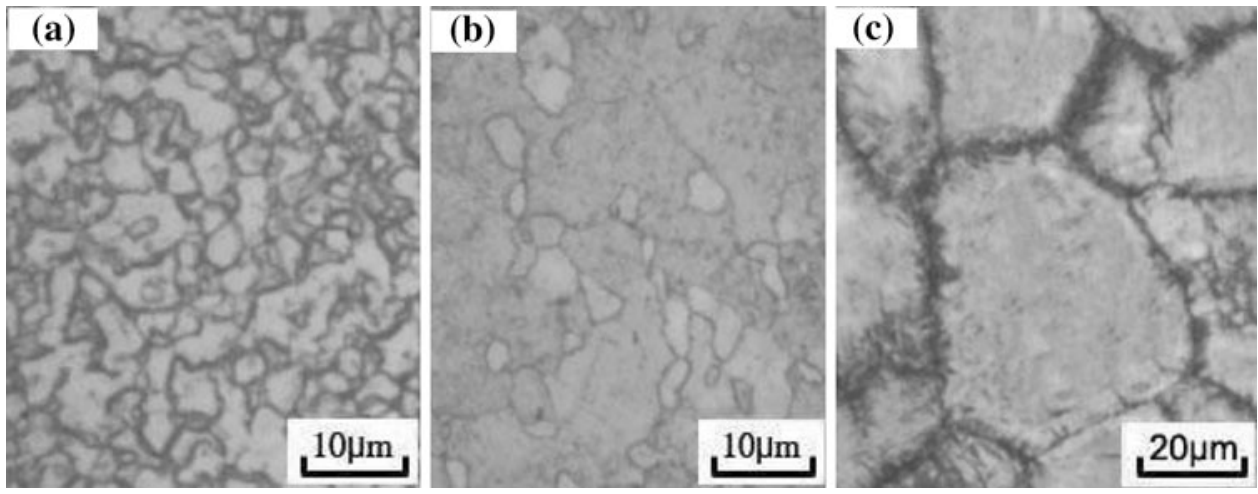

Fig. 8 The microstructure near the fracture at the pre-strain of 2.5 (a) $850{ }^{\circ} \mathrm{C}$ (b) $900{ }^{\circ} \mathrm{C}$ (c) $950{ }^{\circ} \mathrm{C}$

the material plasticity was poor. It indicated that the microstructure property of material was not improved after the clearance stage. When the pre-engineer strain was 2.0, the whole strain in stepped-SPD was the biggest at the three groups of temperature. It showed that the pre-engineer strain induced the recrystallization in order that the grain was refined and the plasticity was enhanced. As shown in Fig. 4, the ability of strain-induced plasticity enhancement decreased with the rising of the deformation temperature because of the trend of grain growth and grain boundary sliding resistance.

\subsection{Microstructrue of Titanium Alloy After Stepped-SPD}

The microstructure of TC6 titanium alloy is shown in Fig. 5-8. When the tensile test happened at the same temperature, the sample grains first decreased and then increased with the pre-strain increase. Compared with the initial organization, the sample grain slightly got thick and its long $\alpha$-phase became equiaxed at the pre-strain of 1.0. The small pre-strain led to the low deformation energy. And the grain size of sample increased with the temperature increase at the same pre-strain. It was reasoned that the recrystallization had less effect on the grain 
growth than the holding time at the high temperature. In contrast, the grain size of sample at pre-strain of 1.5 and 2.0 was smaller than at pre-strain of 1.0. When the deformation energy was gathered to a certain extent by means of increasing the tensile deformation, the dynamic recovery and dynamic recrystallization took place in the sample, resulting in a number of small recrystallized $\alpha$ grains near the grain boundaries of $\alpha$ phase. However, the sample grain at pre-strain of 2.5 got coarse, because the deformation energy stored in the titanium alloys was limited and did not continue to increase with the strain increasing. The long deformation time at high temperature led to the grain growth to a certain degree. That result showed that there was a critical value of pre-deformation of TC6 alloy to induce the grain refinement. And when the prestrain exceeded the critical value, the increase of pre-deformation benefited the grain refinement. The critical pre-deformation of TC6 alloy in stepped-SPD should be near 1.5, and the optimal pre-strain should be about 2.0.

As shown in Fig. 5-8, the impact of temperature on the organization was particularly significant under the condition of the same pre-strain. When the temperature was $850{ }^{\circ} \mathrm{C}$, the small equiaxed $\alpha+\beta$ phase was produced by the dynamic recrystallization. The grains gathered together and then grew at $900{ }^{\circ} \mathrm{C}$ and were bigger than those at $850{ }^{\circ} \mathrm{C}$. The small $\alpha$ phase generated near the grain boundary could pin the grain boundary and prevent the grain from further growing. It could also affect the grain boundary sliding and the superplasticity of the material. As the deformation temperature was $950{ }^{\circ} \mathrm{C}$ close to the transition point of $\beta$-phase, the grain growth rate was greatly improved so that the grain was easy to grow into a thick $\beta$-phase of grain and the grain boundaries got straight which had a significant negative impact on the superplasticity of the material.

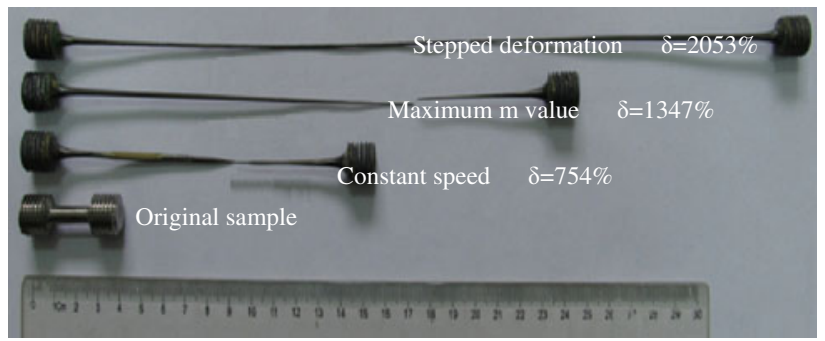

Fig. 9 The sample before and after the three tensile methods

\subsection{The Influence of Deformation Method on Superplasticity}

The tensile test was performed with TC6 titanium alloy via the methods of constant speed, maximum $m$ value, and stepped deformation at $850{ }^{\circ} \mathrm{C}$. All the samples were heated to the testing temperature for $15 \mathrm{~min}$ prior to testing and then were water-quenched immediately when the test finished. The experimental parameter and results are shown as follows:

(1) The constant speed method was adopted and the speed was $1.0 \mathrm{~mm} / \mathrm{min}$ in the tensile test. (2) In the maximum $m$ value method, the initial tensile velocity was $1.0 \mathrm{~mm} / \mathrm{min}$ and the velocity increment was $0.09 \mathrm{~mm} / \mathrm{min}$ per $6 \mathrm{~s}$, because the time with which the sensor recorded data was $6 \mathrm{~s}$ in the data acquisition system. (3) The stepped forming was adopted and divided into two steps which consisted of constant speed and the maximum $m$ value method tension. In the stepped forming method, the samples were first stretched to the designated strain through constant speed of $1.0 \mathrm{~mm} / \mathrm{min}$ method, and then these were performed the heat preservation for $10 \mathrm{~min}$, at last these were continued to stretch with the maximum $m$ value method until their failure.

The tensile result of these three methods is shown in Fig. 9. The maximum $m$ value method obtained more excellent superplasticity than the constant speed method in the tensile test, because the former controlled concurrently the strain rate in such a way that the maximum $m$ was always maintained in the process of the deformation. The tensile elongation of specimen via stepped forming was the largest in these three methods and was $2053 \%$ which was significantly higher than another two methods. It is recognized that the superplasticity enhancement of these alloys is contributed to the grain refinement and structure property improvement at the clearance stage.

The $\mathrm{m}$ values-strain curves obtained from the three test methods were compared. As shown in Fig. 10, it is found that the curves got convex through the stepped-SPD and the maximum $m$ SPD, indicating that the tensile tester always expected the optimal strain rate in the process of the deformation. The $m$ value of the specimen attained from the Stepped-UT and MaxmSPT was significantly higher than the one from constant-speed-method tensile test. Their $m$ value which induced significant superplasticity enhancement was mostly bigger than 0.3 . These three curves showed that the $m$ value decreased as the strain increased. The $m$ value of the specimen obtained from the Stepped-UT was higher than the one from the MaxmSPT, because the pre-deformation provided
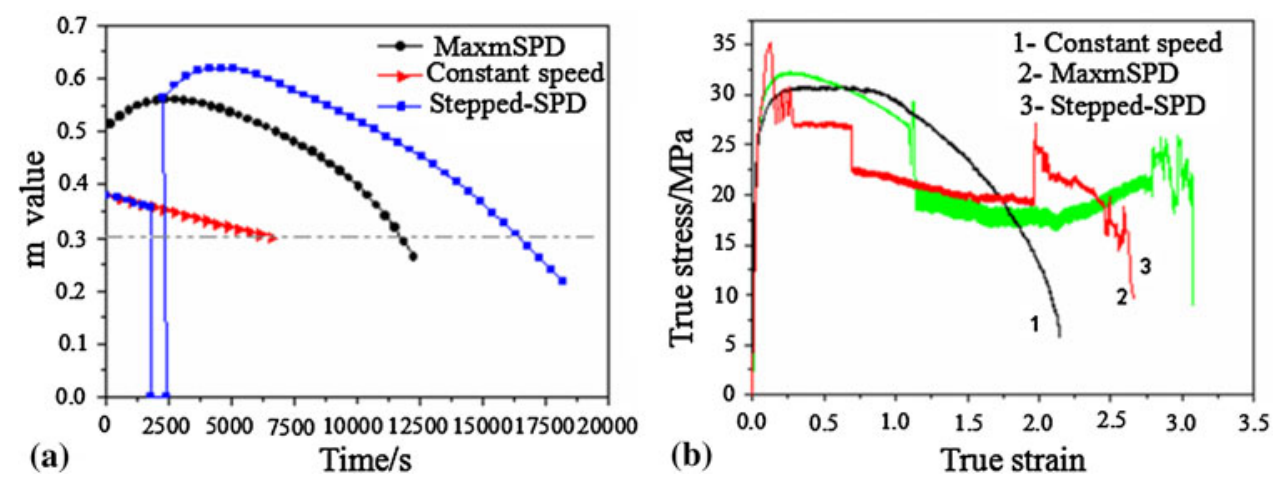

Fig. 10 (a) The $m$ value-time curve of three deformation methods; (b) the true stress-strain curve of three deformation methods 
enough distortion energy for the recrystallization and grain boundary sliding.

\section{Conclusion}

The single-step superplastic deformation generally generates dynamic recrystallization in deformed material. However, the stepped deformation method brings about not only dynamic recrystallization in the deformation process but also the static or meta-dynamic recrystallization at clearance stage between two deformation steps. And that clearance stage resembles the process of heat treating. Thus, the advantage of grain refinement and structure property improvement in the stepped deformation process is more prominent than that in the single-step deformation process and the stepped deformation method is able to obviously enhance the material plasticity. In conclusion, this research presents a promising new stepped deformation process for the realization of the optimal superplasticity.

\section{Acknowledgments}

The authors thank the financial supports from the National Natural Science Foundation of China with Grant Nos. 51075196 and Jiangxi Provincial Department of Education Fund with Grant Nos. GJJ12451.

\section{Open Access}

This article is distributed under the terms of the Creative Commons Attribution License which permits any use, distribution, and reproduction in any medium, provided the original author(s) and the source are credited.

\section{References}

1. R.Z. Valiev, R.K. Islamgaliev, and I.P. Semenova, Superplasticity in Nanostructured Materials: New Challenges, Mater. Sci. Eng. A, 2007, 463, p 2-7

2. P.S. Bate, N. Ridley, and B. Zhang, Mechanical Behaviour and Microstructural Evolution in Superplastic Al-Li-Mg-Cu-Zr AA8090, Acta Mater., 2007, 55, p 4995-5006
3. R. Boyer, G. Welsch, and E.W. Collings, Materials Properties Handbook: Titanium Alloys, J. Mater. Eng. Perform., 1994, 3, p 483-636

4. G.A. Salishchev, R.M. Galeyev, O.R. Valiakhmetov, R.Y. Lutfullin et al., Development of Ti-6Al-4V Sheet with Low Temperature Superplastic Properties, J. Mater. Process Technol., 2001, 116, p 265-268

5. J.S. Kim, J.H. Kim, Y.T. Lee, C.G. Park, and C.S. Lee, Microstructural Analysis on Boundary Sliding and Its Accommodation Mode During Superplastic Deformation of Ti-6Al-4V Alloy, Mater. Sci. Eng. A, 1999, 263, p 272-280

6. C.S. Lee, S.B. Lee, J.S. Kim, and Y.W. Chang, Mechanical and Microstructural Analysis on the Superplastic Deformation Behavior of Ti-6Al-4V Alloy, Int. J. Mech. Sci., 2000, 42, p 1555-1569

7. K. Mallikarjun and S. Satyam, S Bhargava, Effect of Prior b Processing on Superplasticity of $(\alpha+\beta)$ Thermo-Mechanical Treated Ti-632Si Alloy, J. Mater. Process Technol., 2003, 134, p 35-44

8. S.N. Patankar, J.P. Escobedo, D.P. Field, G. Salishchev et al., Superior Superplastic Behavior in Fine-Grained Ti-6Al-4V Sheet, J. Alloys Compd., 2002, 345, p 221-227

9. X.M. Zhan, Y.Q. Zhao, and W.D. Zeng, Effect of Hydrogen on the Superplasticity of Ti40 Alloy with Large Grains, Mater. Sci. Eng. A, 2010, 527(15), p 3489-3492

10. S.Q. Zhang and L.R. Zhao, Effect of Hydrogen on the Superplasticity and Microstructure of Ti-6Al-4V Alloy, J. Alloys Compd., 1995, 218(2), p 233-236

11. X.M. Zhang, Y.Q. Zhao, and W.D. Zeng, Effect of Hydrogen on the Superplasticity of Ti600 Alloy, Int. J. Hydrogen Energy, 2010, 35(9), p 4354-4360

12. Y. Hirofumi and N. Jun, Ultra-Fine-Grain Refinement and Superplasticity of Titanium Alloys Obtained Through Protium Treatment, Int. J. Hydrogen Energy, 2002, 27(7-8), p 769-774

13. A.V. Sergueeva, V.V. Stolyarov, R.Z. Valiev, and A.K. Mukherjee, Enhanced Superplasticity in a Ti-6Al-4V Alloy Processed by Severe Plastic Deformation, Scripta. Mater., 2000, 43(9), p 819-824

14. C.H. Park, Y.G. Ko, J.W. Park, and C.S. Lee, Enhanced Superplasticity Utilizing Dynamic Globularization of Ti-6Al-4V Alloy, Mater. Sci. Eng. A, 2008, 496(1-2), p 150-158

15. Y.T. Wu, C.T. Yang, and C.H. Koo, The Effect of Nb Content on the Superplasticity of Ti-25Al-xNb Alloy, Mater. Chem. Phys., 2002, 73(23), p 212-219

16. X.J. Zhu, M.J. Tan, and W. Zhou, Enhanced Superplasticity in Commercially Pure Titanium Alloy, Scripta. Mater., 2005, 52(7), p $651-655$

17. G.C. Wang, M.W. Fu, C.X. Cao, and H.B. Dong, Study on the Maximum $m$ Superplasticity Deformation of Ti-6.5Al-3.5Mo-1.5Zr0.3Si Alloy, Mater. Sci. Eng. A, 2009, 513-514, p 32-41

18. G.C. Wang and M.W. Fu, Maximum m Superplasticity Deformation for Ti-6Al-4V Titanium Alloy, J. Mater. Process. Technol., 2007, 192-193, p 555-560

19. G.C. Wang, M.W. Fu, H.B. Dong, J. Lu, Q.J. Sun, and C.X. Cao, Superplasticity Deformation of Ti-6Al-2Zr-1Mo-1V Induced by the Cyclic Change of Strain-Rate and MaxmSPD, J. Alloys Compd., 2010, 491(1-2), p 213-217 